\title{
Profilles in Cardiology
}

This section edited by J. Willis Hurst, M.D., and W. Bruce Fye, M.D., M.A.

\section{Lewis Atterbury Conner}

Charles F. Wooley, M.D.

Professor of Medicine Emeritus, Heart Lung Research Institute, The Ohio State University, 473 W. 12th Ave, Columbus Ohio 43210, USA

\section{Lewis Atterbury Conner}

Teacher of medicine, professor and chairman, leader of the heart movement, public health cardiologist, president, editor-in-chief, master of the art and science of physical diagnosis, a man of integrity, and "Cornell's Osler" are titles and descriptors written by those who knew him. Together, they are bits and pieces of the Conner mosaic.

Lewis Atterbury Conner (Fig.1) (1867-1950) was born in New Albany, Indiana, the eldest of 10 children born to Charles Horace Conner and Katherine Boudinot Atterbury. His delightful reminiscences portray his early life in New Albany, a community on the Ohio River across from Louisville, Kentucky. By 1850, New Albany was the largest city in Indiana, a ship building center at the heart of a steamboat economy. Conner grew up on a farm in an environment based on family, church, and work. Following preparatory work at the Chenault School at Louisville, Kentucky, he "came east" to college, attended the Sheffield Scientific School of Yale University and received the degree of Bachelor of Philosophy in 1887. Three years later, he received his medical degree from the College of Physicians and Surgeons of Columbia University. After serving as a house officer at New York Hospital from 1890 to 1892, Conner spent

Address for reprints:

Charles F. Wooley, M.D.

Professor of Medicine Emeritus

Heart Lung Research Institute

The Ohio State University

473 W. 12th Ave, Columbus Ohio 43210, USA

e-mail: Charles.wooley@osumc.edu

Received: August 7, 2006

Accepted with revision: August 18, 2006

Published online in Wiley InterScience

(www.interscience.wiley.com).

DOI: $10.1002 /$ clc. 13

(C) 2007 Wiley Periodicals, Inc.
2 years in Vienna, Munich and Heidelberg as a postgraduate student. He returned to practice medicine in New York City in 1894.

\section{Teacher, Professor, and Chairman}

Most of Conner's career was spent at New York Hospital and Cornell University Medical College. Appointed as an Instructor in Medicine in the original faculty at Cornell in 1898, he was promoted to professor of clinical medicine in just 2 years. ${ }^{1}$ At that time he was also an Attending Physician to the New York Hospital's House of Relief on Hudson Street and an Assistant Pathologist to the New York Hospital. ${ }^{1} \mathrm{He}$ would eventually succeed W. Gilman Thompson as professor of medicine in 1916. At this time, the department of medicine also included the Russell Sage Institute of Pathology affiliated with the second medical service of Bellevue Hospital, the Cornell division. The faculty roster included several clinical investigators who contributed to the excellent research productivity of the department in the 1920s. With the opening of the "new" New York Hospital-Cornell Medical Center in 1932, Eugene F. DuBois replaced Conner as the Chairman of the Department of Medicine. ${ }^{1}$

\section{Military Physician}

Conner's first military experience, in 1898, was as a private in the Spanish-American War. During World War I, he was a senior officer in the U.S. Army Medical Corps. The army was updating the physical examination process, replacing and revising the 1910 version of its Rules for Examination of Recruits. The traditional approach to evaluating the health and physical condition of recruits was viewed as outdated. It was based on nineteenth century clinical pathologic correlates derived from patients with late stage disease. This was thought to be of limited value when it came to the systematic examination of almost four million young men. The need to revise the cardiovascular physical examination standards and terminology was paramount. 


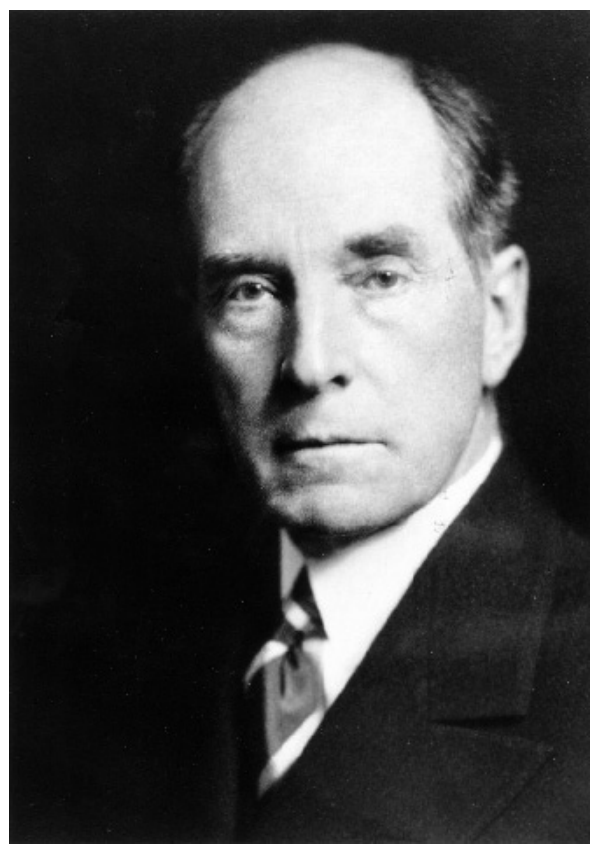

FIG. 1 The mature Lewis Conner. Courtesy of the Medical Archives, New York Hospital-Cornell Medical Center.

In 1917, Conner was appointed Chief of the Army Medical Corps Division of Internal Medicine, with the rank of Major. He was involved in the selection and training of the cardiovascular specialists whose responsibilities included the interpretation of cardiovascular signs and symptoms. They were also expected to reconcile cardiovascular physical findings with the military criteria for fitness for duty. Later in the war, Conner represented the Surgeon General's Office in the implementation of the first Cardiovascular Medical Center at U.S. Army Hospital \#9 at Lakewood, New Jersey. Discharged in the rank of Colonel in 1919, he was appointed a Brigadier General in the Reserve Corps in 1919. Conner was anxious to incorporate knowledge gained during the war about cardiac diagnosis, the etiology of cardiac disorders, functional disorders of the heart, and valvular heart disease into civilian medical practice. ${ }^{2}$ Many of his observations and conclusions from his military experiences surfaced in his later publications and in his discussions of papers presented at the American Heart Association meetings. ${ }^{3}$

\section{Public Health Cardiologist -Leader in the Heart Movement}

Early in his career, Conner directed his attention to heart disease as a public health problem and to the rehabilitation of cardiac patients. His active participation in the development of the New York Heart Association and the American Heart Association was an expression of his commitment to the developing "heart movement." During this time his involvement extended to the establishment of the cardiac convalescent home, cardiac classes,
The Trade School for Convalescents, and specialty outpatient clinic programs. In his landmark 1927 article on rehabilitation, Conner quoted Frederic Brush on the appropriation of public and private funds for the care of cardiac patients. There was a major differential in the cost of care for the cardiac patient in the hospital ( $\$ 30$ per week), the convalescent home (\$12 per week), and the special cardiac clinic ( $\$ 1$ per week).

"Public Health Cardiologists" is a term used to describe a select group of physicians who were concerned with the provision of both medical and social services to cardiac patients. They also played a major role in the establishment and the agenda of organizations devoted to cardiac disease. ${ }^{4}$ These public health cardiologists focused on the prevention of heart disease, the rehabilitation of patients with cardiac disability, and the social and economic consequences of cardiac disease in addition to diagnosis and treatment. Conner's activities from the cardiac clinic to the convalescence of working men with cardiac disease led to the creation of the Association for the Prevention and Relief of Heart Disease in 1915. He served as the first president of this group that brought together physicians and laypersons concerned about the frequency and social consequences of cardiac disease.

The introduction of the chest x-ray, the electrocardiograph, and the World War I medical experiences all contributed to the development of cardiac specialists. Meanwhile, Conner's wartime observations contributed to the growing awareness about the epidemiology of heart disease, its etiology and frequency in specific age groups and in the population at large. A group of distinguished men and women were involved in the next stages of the development of an organized approach to patients with cardiac disease. They formed the New York Heart Association in 1916, and were central figures in the creation of the American Heart Association 8 years later. These were important steps in the developments in American cardiology in the early twentieth century. Lewis Conner played a major role in all these events.

\section{President and Editor-in-Chief}

Conner was one of the founders and the first president (1924-25) of the American Heart Association. A memorial lecture at the annual meeting now bears his name. He was also the first editor-in-chief of The American Heart Journal, the official organ of the American Heart Association, which began in 1925. His editorial "The American Heart Journal" appeared in the first issue of the new journal in October 1925. Conner emphasized the importance of the new journal that was established to foster the "newly awakened" widespread interest in circulatory diseases. The journal would emphasize the preventative aspects and public health relations of heart diseases, as well as scientific developments. This was the 
first periodical in North America devoted to cardiac disease. Conner was convinced that the journal would be a potent factor in the furtherance of the aims and goals of the American Heart Association. Moreover, one essential first step in the new campaign against cardiac disease was to enhance the education of the medical profession in matters relating to the diagnosis, treatment, and prevention of heart diseases. Clinical studies, special research, and public health aspects were important subjects to be covered in the American Heart Association publication.

\section{Master of the Art and Science of Physical Diagnosis, a Man of Integrity}

William Paul Thompson, a prominent cardiologist of Los Angeles, was in the last group of interns trained by Lewis Conner at the "old" New York Hospital. Thompson recalled Conner as a tall man, with red fringes surrounding his bald head, who was exceedingly dignified. A scholarly gentleman physician who was kind to patients and staff, Conner was noted for his meticulous physical examinations. Thompson provided a compelling picture of the man known as "Chief," a superb clinical teacher; serving as a house officer under him was "such a great joy."1

\section{"Cornell's Osler"}

High praise indeed, but Fisher makes a strong case portraying the Osler-Conner parallels, recalling Conner's role as an extraordinary clinician, father of cardiac rehabilitation in America, a humanist with great equanimity, dedicated to the Oslerian tradition of scholarship, leadership, and organization in the quest for improved patient care. ${ }^{5}$ For many reasons, Lewis A. Conner occupies a unique place in cardiology in America.

\section{References}

1. Wooley CF, Schneider D, Lerner AA. Lewis atterbury conner: appreciation and bibliography. Circulation 1998;98:1449-1455

2. Conner LA. Cardiac diagnosis in the light of experiences with army physical examination. Am J Med Sci 1919;158:779-782

3. Wooley CF, Lewis A, Conner MD. (1867-1950), and lessons learned from examining four million young men in World War I. Am J Cardiol 1988;61:900-903

4. Fye WB: American cardiology. The History of a Specialty and its College. Baltimore, London: The Johns Hopkins University Press 1996; 36-84

5. Fisher J, Lewis A. Conner: cornell's osler. Circulation 2000;102: 1062-1067 